\title{
Students' views of learning about an interprofessional world café method
}

\author{
G C Filies, ${ }^{1}$ MPhil; Z Yassin, ${ }^{2}$ MCFS; J M Frantz, ${ }^{3} \mathrm{PhD}$
}

${ }^{1}$ Interprofessional Education Unit, Faculty of Community and Health Sciences, University of the Western Cape, Cape Town, South Africa

${ }^{2}$ Child and Family Studies Unit, Faculty of Community and Health Sciences, University of the Western Cape, Cape Town, South Africa

${ }^{3}$ Department of Physiotherapy, Faculty of Community and Health Sciences, University of the Western Cape, Cape Town, South Africa

Corresponding author: G C Filies (gfilies@uwc.ac.za)

Background. Interprofessional education (IPE) and practice were conceived as a means to improve quality of care by bringing together the health and social professions to learn and work collaboratively in teams. This collaboration in turn would assist in overcoming negative stereotypes, and promote an understanding and value of the roles of the different professions.

Objective. To highlight a specific methodology to advance the interprofessional learning of senior students across five disciplines. By sharing the views of students engaged in a world café model of IPE, the authors highlight this strategy as a new concept in instilling core competencies in students. This in turn may assist other higher education institutions in their own processes of creating interprofessional curricula opportunities.

Methods. The participants included senior students from university departments of physiotherapy, oral health, social work, pharmacy and nursing. At the conclusion of the world café sessions, students evaluated the process by means of a questionnaire, using associative group analysis methodology. The responses were analysed into themes according to questions posed to students in an evaluation questionnaire.

Results. It was evident that students understood the terminology of IPE and learnt from others in terms of their roles and responsibilities within a team. Overall, students valued the experience; however, they emphasised the need for additional authentic learning opportunities throughout their student training.

Conclusion. It is evident that although higher education institutions create opportunities for interprofessional learning, similar opportunities need to be provided in the practice setting.

Afr J Health Professions Educ 2016;8(2 Suppl 2):229-233. DOI:10.7196/AJHPE.2016.v8i2.844

Interprofessional education (IPE) is a process that prepares professionals, through collaborative learning and diverse fieldwork experiences, to work in partnership with communities to meet the multifaceted needs of society. ${ }^{[1]}$ It is a process that assists in providing the knowledge, skills and values needed by health professionals to collaborate effectively with other health professionals as they serve families and communities. IPE allows health professionals to overcome the lack of knowledge of basic concepts in collaboration and issues facing other professions. ${ }^{[2]}$ Preparing future healthand social-care professionals to work together with future colleagues would assist in fostering interprofessional collaboration in the clinical setting. ${ }^{[3]}$ IPE is viewed as a collaborative approach to the development of healthcare students as future interprofessional team members, and their viewpoint is based on an understanding that complex health and social challenges are best addressed by interprofessional teams. ${ }^{[4]}$ However, starting an IPE programme poses unique challenges that may not be encountered when starting a more traditional, discipline-specific programme.

In South Africa (SA), promising developments towards transforming health professionals' education are taking place, indicating a positive shift to IPE opportunities. ${ }^{[5]}$ These developments include moving away from discipline-focused faculties to health sciences faculties that include at least two or more allied health disciplines; integration of interprofessional core courses in the undergraduate health professions curricula, which are commonly developed around health, primary healthcare, health promotion and ethics; and moving away from the teaching hospital to the teaching platform, which includes hospitals, clinics and communities. In other words, these developments comprise application of this concept to all levels of care and the extension of collaboration among faculties in the provinces, where clinical platforms are shared with provincial health authorities.

Various strategies are used to implement IPE and practice, including the world café methodology ${ }^{[4,6]}$ The world café process is based on seven key design principles: setting the context and understanding why groups are being brought together; creating a hospitable space that encourages trust; exploring questions that are relevant to real-life situations faced by the group; encouraging participation and connecting diverse perspectives; collectively considering the different perspectives; and, finally, sharing collective discoveries. Thus, the world café can allow the collective intelligence of a group to emerge and increase people's capacity for effective action in the pursuit of common aims. This approach has been shown to assist students in engaging with IPE. ${ }^{[7]}$ This article describes the views of students with regard to the use of the world café methodology to learn about interprofessionalism in healthcare professionals.

\section{Methods \\ Research setting}

A world café is conducted once per academic term for all senior students as part of interprofessional activities in the Faculty of Community and Health Sciences (FCHS), University of the Western Cape (UWC), Cape Town, SA. The FCHS had revised its undergraduate curriculum by incorporating core interdisciplinary modules into the 4-year undergraduate curriculum of its health professions programmes (physiotherapy, psychology, human ecology, complementary medicine, occupational therapy, social work, sport, recreation and exercise science, dietetics and nursing) in response to the health and social needs of society. 


\section{Population and sampling}

The population consisted of undergraduate students from the FCHS. An open invitation was sent to all interprofessional departmental representatives to participate in the world café initiatives. Timetable slots were indicated at the beginning of the year by the co-ordinating unit, allowing departments to plan accordingly. Departments that responded included Nursing, Physiotherapy, Occupational Therapy, Social Work, Oral Health, Pharmacy, Sports Management and the School of Natural Medicine, which amounted to 653 students from the different professions over a 3-year period (2013 2015). Not all students participated at the same time, as participation was dependent on student availability.

\section{Data collection methods}

This article reports on the data collected through evaluative questionnaires of five disciplines (nursing, physiotherapy, oral health, pharmacy, social work) that have consistently participated in the world cafés over the 3 -year period $(N=171)$. At the end of every world café session, students evaluated the process and experience by means of a questionnaire, using the associative group analysis (AGA) questionnaire (Table 1). The objective of the questionnaire was for students to share what they had learnt from their engagement in the world café education activity. The questions were phrased in such a way that the students listed their responses consecutively. Thus, each question would have at least three responses or phrases that were captured per participant.

\section{Interprofessional world café intervention}

The interprofessional world café (IPWC) was designed to create an opportunity for students to have a discussion around specific cases, and incorporated the core interprofessional competencies as a measure towards collaborative practice. Through brief didactic input, initial theoretical positions were introduced to students in an attempt to raise their awareness of the subject, and initiate reflection opportunities for them to consider the key concepts of IPE. ${ }^{[8]}$ During the small-group discussions the learning experience was, therefore, a shared dialogue between the facilitator and students. The facilitator asked probing questions about the case study to allow student teams to develop an intervention care plan for presentation purposes to the plenary. This allowed the values and beliefs that underpinned the thoughts and statements of the students to emerge. The students could also ask questions of the facilitator and each other. The dialogue progressed interactively and the facilitator was as much a participant as a guide of the discussion. ${ }^{[9]}$

Tables were set up, café style, with flip chart paper covering the tables. Each table was hosted by a facilitator (staff member) for the duration of the programme. Dialogue was facilitated with groups of six to eight students around a specific question that aimed to generate discussion towards the development of an interprofessional care plan. Coming from specific departments in the faculty, the students each brought to the table not only their disciplinary expertise but the competencies they had developed through training in their early years in IPE in such areas as collaboration. Students spent 20 minutes at a table discussing a specific question, after which they moved on to another table for the next round of discussions. Students were not required to remain in the same group, but were required to visit each table with a different question. Students could rotate to different tables based on which questions they needed answered in the development of their understanding of interprofessional competence towards collaborative practice. At the end of the session (six 20-minute rounds of dialogue) students convened in their original groups and were given a case study with a set of questions. Using all the information they had gathered from the different discussion rounds, the interprofessional student teams were then required to develop a poster presentation based on a case study, and respond to any questions from the plenary following their presentation. Faculty members could use this opportunity to evaluate students as part of their clinical practice modules.

\section{Data analysis}

This method of analysis offers an opportunity for a greater depth of content analysis. ${ }^{[9]}$ The basic unit of analysis is the stimulus word or theme word. ${ }^{[10]}$ As the study focused on interprofessionalism, the AGA methodology aimed to explore thinking patterns and determine how the students perceived and evaluated the concept of interprofessional practice. ${ }^{[10]}$ The responses were in the

Table 1. Key questions

A. Using an interprofessional approach to patient care:

What is the first thing that comes to mind when you think about using an interprofessional approach to patient care?

What is the second thing that comes to mind when you think about using an interprofessional approach to patient care?

What is the third thing that comes to mind when you think about using an interprofessional approach to patient care?

B. With reference to working as part of an interdisciplinary healthcare team during your training:

1. What is the first thing that comes to mind when you think about working in an interdisciplinary team?

2. What is the second thing that comes to mind when you think about working in an interdisciplinary team?

3. What is the third thing that comes to mind when you think about working in an interdisciplinary team?

C. With reference to your prior exposure to interprofessional teaching and learning activities, how does this contribute to your development as a healthcare professional?

1. What is the first benefit that comes to mind when you think about your earlier exposure and its contribution to your development as a team member?

2. What is the second benefit that comes to mind when you think about your earlier exposure and its contribution to your development as a team member?

3. What is the third benefit that comes to mind when you think about your earlier exposure and its contribution to your development as a team member?

D: Criteria to measure the impact of interprofessional health care (IPHC).

1. List at least three criteria that should serve as indicators of success when measuring the impact of IPHC. 
form of one word or short phrases. The data were captured verbatim from the open-ended questions in a Microsoft Excel (USA) spreadsheet and analysed into themes, and are presented accordingly. ${ }^{[1]}$ Ethical clearance for the study was obtained from the UWC ethics committee (project no. 14/9/25).

\section{Results}

The questionnaires were completed by 1713 rd- and 4 th-year students across five different professions, including physiotherapy $(n=19)$, oral health (18), social work ( $n=24)$, pharmacy $(n=12)$ and nursing $(n=98)$. The average age of the students was 23.4 years and $84.5 \%$ of the 171 students were female. Predominant clusters and verbal responses to the interprofessional learning opportunity (world café) are presented in the tables. These tables highlight the key responses, particularly those that were repeated more than once.

The sections below present students' understanding of the interprofessional approach to care - what it entailed, its benefits to the patient and the healthcare professional, and possible criteria to evaluate the impact of IPE and practice. How and what students learnt about interprofessionalism from engaging in the world café activity is also reflected below.

\section{Interprofessional approach to care}

In response to the question that explored the students' understanding about an interprofessional approach to care, seven common responses emerged: communication, collaboration/teamwork, competence, interdisciplinary, multidisciplinary, model of care, and shared responsibility (Table 2).

Several students stated that an interprofessional approach entailed multiple health professionals working together in a team with a common goal to achieve their objectives. Participants expressed the benefits of this model of care because it provides holistic care for the patient/family/community, it provides an approach for optimum care, and is a better model of care than the individual professional approach. Collaboration and communication were considered the greatest components of an interprofessional approach to patient care. In addition, collaboration allowed for the integration of knowledge and experience of health professionals, leading to combined interventions that promoted a holistic model of care.

Interprofessional communication was recognised as an essential tool to facilitate discussions and interactions while enhancing team function.
Effective collaboration and communication were seen as contributing to the competence of health professionals, as they developed a variety of skills and mutual respect for one another while gaining knowledge about the roles and responsibilities of other health professions. Competence in the skills related to a health professional was also identified as the attainment of interpersonal skills and understanding aspects such as advocacy, ethics and punctuality.

Despite the perceived benefits of an interprofessional approach to patient care, multidisciplinary challenges were highlighted by participants. Interprofessional collaboration was identified as a challenging process between health professionals as a result of ineffective communication through the use of discipline-specific terminology, the lack of clarity of roles and responsibilities, the feeling of superiority as health professionals dispute which profession is deemed superior or the best, and the belief that effective collaboration is impossible and cannot be achieved.

\section{Teamwork as part of health professionals' education training}

Four key themes pertaining to the question about teamwork as part of their health professions education training emerged: collaboration, roles and responsibilities, model of care, and a multidisciplinary approach to care (Table 3). Collaboration was identified as an essential component in health professionals' education training, as participants recognised the need for other professionals' assistance and the promotion of good health. Similarly, roles and responsibilities were also deemed pertinent to the theme of teamwork and involved sharing of the responsibilities associated with patient care. Each health professional, as part of the interdisciplinary team, is needed, as they play a significant role in patient management and care required for the restoration of optimal health. Additionally, each disciplinary expert possesses knowledge and various skills needed for the diagnosis and treatment of a patient.

\section{Interprofessional teaching and learning activities and their contribution to the development of future healthcare professionals}

Interprofessional teaching and learning activities were identified as contributing to the development of competence and skills, improved understanding and improved knowledge of participants (Table 4). Participants demonstrated

Table 2. Benefits of using an interprofessional approach of care

\begin{tabular}{ll}
\hline $\begin{array}{l}\text { Predominant clusters } \\
\text { Communication }\end{array}$ & $\begin{array}{l}\text { Verbal responses } \\
\text { Competence }\end{array}$ \\
$\begin{array}{l}\text { Communication and respect, teamwork and communication, effective communication, good communication, educating the patients } \\
\text { Respect for other health professionals, variety of skills, integration of skills, responsibility, mutual respect, knowledge of the } \\
\text { professions, interpersonal skills, understanding each other, advocacy, ethics, punctuality }\end{array}$ \\
Interdisciplinary & $\begin{array}{l}\text { Collaborative input to patient care, collaboration with different disciplines, collaboration of health professionals in the treatment } \\
\text { of a patient, teamwork } \\
\text { Management of the patient's condition by getting help from other professions, working towards a common goal - treatment of } \\
\text { patient, sharing and working towards a common goal }\end{array}$ \\
Model of care & $\begin{array}{l}\text { Holistic care of patient, the patient will receive holistic care, better model of care, holistic approach, optimum patient care } \\
\text { Taking care of the patient's health needs as a multidisciplinary team, working together as different professionals, working } \\
\text { together to promote health }\end{array}$ \\
Shared responsibility & $\begin{array}{l}\text { Each person in a team takes different responsibilities for giving care, different roles and responsibilities of professionals, each } \\
\text { person in the team providing their field of expertise, sharing of workload } \\
\text { Challenging process between professionals, differences of opinion as to which profession is best, not happening, not possible }\end{array}$
\end{tabular}




\begin{tabular}{|c|c|}
\hline Predominant clusters & Verbal responses \\
\hline Collaboration & $\begin{array}{l}\text { Help each other in order to promote good health } \\
\text { Combined efforts make the objective easier to achieve } \\
\text { It was helpful in knowing other groups that we work with in the hospital and } \\
\text { sharing ideas } \\
\text { Every profession contributes to make a change } \\
\text { Everyone assists in the final outcome }\end{array}$ \\
\hline Model of care & $\begin{array}{l}\text { Patient care was easier } \\
\text { We can provide better specialised care for the patient } \\
\text { Holistic improvement of health skills and patient's health } \\
\text { Good approach to treating the patient } \\
\text { To manage patients in order to promote their wellbeing } \\
\text { Makes the case easier and brings about more effective results }\end{array}$ \\
\hline Multidisciplinary & $\begin{array}{l}\text { We need each other } \\
\text { Involve everybody but always remain equal } \\
\text { All the disciplines connect in a way }\end{array}$ \\
\hline $\begin{array}{l}\text { Roles and } \\
\text { responsibilities }\end{array}$ & $\begin{array}{l}\text { Sharing responsibility for a patient } \\
\text { Each discipline has a role to fulfil in restoring the patient to optimum health } \\
\text { Playing significant role in patient management } \\
\text { Each discipline carries weight for diagnoses }\end{array}$ \\
\hline
\end{tabular}

Table 4. Value of interprofessional teaching and learning activities

\begin{tabular}{ll}
\hline Predominant clusters & Verbal responses \\
\hline $\begin{array}{l}\text { Improved competence } \\
\text { and skills }\end{array}$ & $\begin{array}{l}\text { Improved respect and values, learnt how to master skills, practised ethics } \\
\text { together, skills development, interpersonal skills development }\end{array}$ \\
Improved & $\begin{array}{l}\text { Helped understand what other disciplines do } \\
\text { Bnderstanding }\end{array}$ \\
& $\begin{array}{l}\text { Fully understand why each one of us should work as a team } \\
\text { Understanding the importance of others }\end{array}$ \\
Improved knowledge & $\begin{array}{l}\text { Increased my knowledge of other professions } \\
\text { Gained information from the different professions of healthcare of the patient } \\
\text { Gained knowledge of the roles and responsibilities of the different healthcare } \\
\text { professionals } \\
\text { It opened up my mind to know what the other disciplinary teams do }\end{array}$
\end{tabular}

enhanced competence and more respect for other disciplines and health professionals as they became more knowledgeable about the scope and practice of other health professions, and acknowledged an increase in the value of the roles and contributions of other healthcare professions. Interprofessional training and teaching assisted in the development of interpersonal and professional skills, as participants described effective communication, respect, attentiveness, mutual understanding, active listening, participation, punctuality, passion, unity and ethical practice as a collaborative team. Interprofessional teaching and learning activities provided participants with an understanding of the scope and practice of other disciplines and the value and importance of teamwork in rendering effective, efficient and reliable healthcare services. Moreover, participants reported being more knowledgeable about the roles and responsibilities of healthcare professionals and how these professionals may contribute to the management and care of a patient. According to participants, an increase in knowledge allows for a more effective model of care as health professionals make appropriate referrals and consult various other health professionals when unable to address or effectively treat a patient.

\section{Criteria used to measure the impact of interprofessional teaching and learning activities}

Students' suggestions of the criteria that can serve as indicators to measure the impact of interprofessional teaching and learning included authentic learning opportunities, patient involvement, patient outcomes, improved research, communication and workshops (Table 5). Participants believed that authentic learning activities or creative measures may promote interprofessional practices in a reallife setting. Patient feedback, evaluation of a patient's health and improvement of a patient's condition were recognised as good measures of the outcomes of interprofessional teaching and learning activities. Communication was identified as a means of measurement, as participants were able to offer constructive criticism, effectively communicate with or within a multidisciplinary team and develop mutual respect for one another. Other methods found to measure impact included focus groups, questionnaires, reflective journals, portfolios, social media, videos and observation during clinical practice.

\section{Discussion}

According to our findings, the world café is viewed as a distinct model of IPE and practice. The model has been recognised as successfully contributing to a student's ability to work in a multidisciplinary team, promoting skills for holistic care and aiding the development of health professionals. Aligned with the findings of the study, IPWC is an example of authentic learning, as students participate in real-life problems. By engaging in the IPWC, students are taught how to work in interprofessional teams in practical settings. If students are exposed to interprofessional learning opportunities, they are likely to translate these experiences into practice. By doing this, they use their acquired skills and knowledge, which could be needed in the workplace at a future stage. ${ }^{[12]}$

Similarly, the world café has been recognised for assisting students in engaging in IPE, which involves professional collaboration by communication or dialogue. ${ }^{[6]}$ The IPWC has created an opportunity for dialogue between students, which equips them with key competencies regarding interprofessional collaboration and care. These competencies include communication, collaboration, teamwork, identifying roles and responsibilities, planning a holistic model of care, sharing responsibility for patient care and developing health professional competence.

The collaboration achieved through IPWC played a significant role in highlighting the importance of promoting a better model of care through the attainment of common goals. 
Table 5. Criteria to measure interprofessional education activities

\begin{tabular}{|c|c|}
\hline Predominant clusters & Extracts of verbal responses \\
\hline $\begin{array}{l}\text { Authentic learning } \\
\text { opportunities }\end{array}$ & $\begin{array}{l}\text { Students to be more creative and go out more to deal with situations } \\
\text { Are we able to use what we are being taught, in a proper manner and where } \\
\text { it counts? } \\
\text { Activities can be done in order to promote and encourage interpersonal/ } \\
\text { multidisciplinary practices in real situations } \\
\text { All disciplinary teams must be available in the clinical setting }\end{array}$ \\
\hline Patient involvement & $\begin{array}{l}\text { Feedback from the patients or clients } \\
\text { Listen to response from the patients } \\
\text { Get feedback on how the patient made progress with interprofessional care }\end{array}$ \\
\hline Patient outcomes & $\begin{array}{l}\text { Is there a decrease in prevalence of disease burden? } \\
\text { Evaluating the patient as the bigger role player } \\
\text { Improvement in the patient. How does it impact on the patient? } \\
\text { See if the patient's condition has improved after meeting with } \\
\text { interprofessional team }\end{array}$ \\
\hline $\begin{array}{l}\text { Improved } \\
\text { communication }\end{array}$ & $\begin{array}{l}\text { Interact with others in the team } \\
\text { Constructive criticism and mutual respect should be encouraged } \\
\text { Make sure that different disciplines do not undermine each other, and } \\
\text { communicate well } \\
\text { Learn to share ideas with other groups } \\
\text { Make sure all disciplines have adequate training and especially work on } \\
\text { developing communication skills }\end{array}$ \\
\hline Research & $\begin{array}{l}\text { Surveys and interviews should be done to measure the impact of the } \\
\text { interprofessional teaching and learning activities } \\
\text { Survey on patients to see whether professions are working together and if this } \\
\text { promoted their understanding }\end{array}$ \\
\hline Workshops & $\begin{array}{l}\text { Discussions among different health professionals on a monthly basis through } \\
\text { workshops } \\
\text { Workshops for interdisciplinary teams should take place }\end{array}$ \\
\hline
\end{tabular}

Similarly, D'Amor et al. ${ }^{[13]}$ have described the promotion of interprofessional collaboration as an efficient, effective and satisfying way to offer healthcare services. Students described their combined efforts to reach a common goal as helpful and promoting a better model of care. Similarly, the IPE and dialogue promoted by IPWC allow for specialised and integrated interventions that address the holistic health and wellbeing of a patient. These integrated interventions are recognised for their ability to yield more effective results within a real-life setting. ${ }^{[14,15]}$ Therefore, IPWC can be used as an authentic learning experience that facilitates the promotion of IPE and practice in health professional students.

\section{Conclusion}

It was evident that students understood the meaning of IPE, even though they used various terms interchangeably. They learnt from other students about their roles and responsibilities and could function as a team to complete the various tasks during the IPWC. The students understood the attributes needed to function within a team and improve their knowledge and skills. Students ultimately emphasised the need for authentic learning experiences where two or more disciplines were present in the clinical setting.

Acknowledgements. The authors thank the departments, students and community stakeholders for their participation in the interprofessional programmes. Furthermore, we wish to acknowledge Dr F Waggie, Mrs C Fester, Mr J Appolis, Ms A Simpson, Mrs R Hull and Mrs I Fredericks for their support and assistance in the development of IPE and practice at UWC.

\footnotetext{
References

1. Canadian Interprofessional Health Collaborative. A national interprofessional competency framework, 2010. http://www.cihc.ca/ resources/publications (accessed 25 April 2015)

2. McNair RP. The case for educating health care students in professionalism as the core content of interprofessional education. Med Educ 2005;39(5):456-464. DOI:1111/j.1365-2929.2005.02116.x

3. Dumont S, Brière N, Morin D, Houle N, Iloko-Fundi M. Implementing an interfaculty series of courses on interprofessional collaboration in prelicensure health science curriculums. Educ Health 10 (online) 2010;23(1):395. http://www.educationforhealth.net/article (accessed 27 May 2016).

4. Bridges DR, Davidson RA, Odegard PS, Maki IV, Tomkowiak J. Interprofessional collaboration: Three best practice models of interprofessional education. Med Educ Online 2011;16. DOI:10.3402/ meo.v16i0.6035

5. Mpofu R. Interprofessional education for collaborative health care in South Africa. Workshop of the South African Committee Health Science Deans, 3 July 2012 UKZN. http://shs.ukzn.ac.za/SACOHSD/ Presentation.aspx (accessed 11 June 2016).

6. Brown J, Isaacs D. World Café Community. The world café: Shaping our futures through conversations that matter. San Francisco: BarrettKoehler Publishers, 2005.

7. Terry J, Raithby M, Cutter J, Murphy F. A menu for learning: A world café approach for user involvement and interprofessional learning on mental health. Social Work Educ 2015;34(4):437-458. DOI: on mental health. Social Wo

8. Banning M. Approaches to teaching: Current opinions and related research. 8. Banning M. Approaches to teaching: Current opinions and related research
Nurse Educ Today 2005;25(7):502-508. DOI:10.1016/j.nedt.2005.03.007

9. Reich R. The Socratic method: What it is and how to use it in the classroom. Speaking of Teaching 2003;13(1):1-4

10. Zlotnick JL, McCroskey J, Gardner S, et al. Myths and Opportunities: An Examination of the Impact of Discipline-specific Accreditation on Interprofessional Education. Alexandria, VA: Council on Social Work Education, 1999:75,77.

11. Peterson M, Martin SS. Associative group analysis: A tobacco prevention case study. Soc Mar Q 2003;9(2):32-49. DOI:10.1080/15245000309100

12. Snyman S, von Pressentin KB, Clarke M. International Classification of Functioning, Disability and Health: Catalyst for interprofessional education and collaborative practice. J Interprof Care 2015;29(4):313319. DOI:10.3109/13561820.2015.1004041

13. D'Amour D, Ferrada-Videla M, San Martin Rodriguez L, Beaulieu MD The conceptual basis for interprofessional collaboration: Core concepts
The The conceptual basis for interprofessional collaboration: Core concepts
and theoretical frameworks. J Interprof Care 2005;19(Suppl 1):116-131.
DOI:10.1080/13561820500082529

14. Cullingham C, Scott C, Lagendyk L. Primary healthcare models through the lens of Alma Ata. 2008. http://compaircanada.ca/system/ files/PHC+Models+Final+Feb+2008.pdf (accessed 17 June 2016).

15. O'Daniel M, Rosenstein AH. Professional communication and team collaboration. In: Hughes RG, ed. Patient Safety and Quality: An Evidence-Based Handbook for Nurses. Rockville, Md: Agency for Health Care Research and Quality, 2008.
} 